\title{
The pH optimum of native uracil-DNA glycosylase of Archaeoglobus fulgidus compared to recombinant enzyme indicates adaption to cytosolic pH
}

\author{
Ingeborg Knævelsrud ${ }^{1}$,2, Sabina Kazazic, Nils-Kåre Birkeland², and Svein Bjelland ${ }^{\bowtie}$ \\ 1Faculty of Science and Technology, Department of Mathematics and Natural Sciences-Centre for Organelle Research, University of Stavanger, \\ Stavanger, Norway; ${ }^{2}$ Department of Biology and Centre for Geobiology, University of Bergen, Bergen, Norway
}

\begin{abstract}
Uracil-DNA glycosylase of Archaeoglobus fulgidus (Afung) in cell extracts exhibited maximal activity around $\mathrm{pH}$ 6.2 as compared to $\mathrm{pH} 4.8$ for the purified recombinant enzyme expressed in Escherichia coli. Native Afung thus seems to be adapted to the intracellular $\mathrm{pH}$ of $A$. fulgidus, determined to be $7.0 \pm 0.1$. Both recombinant and native Afung exhibited a broad temperature optimum for activity around $80^{\circ} \mathrm{C}$, reflecting the $A$. fulgidus optimal growth temperature of $83^{\circ} \mathrm{C}$. Adaption to the neutral conditions in the $A$. fulgidus cytoplasm might be due to covalent modifications or accessory factors, or due to a different folding when expressed in the native host.
\end{abstract}

Key words: DNA repair, uracil-DNA glycosylase, uracil, deamination, hyperthermophiles

Received: 09 January, 2014; revised: 24 April, 2014; accepted: 02 May, 2014; available on-line: 16 June, 2014

\section{INTRODUCTION}

Hydrolytic deamination of cytosine to uracil is, after depurination, the most frequent damaging event to DNA. Such uracils in DNA result in G.C to A.T transition mutations if they are not repaired before replication (Lindahl, 1993). In addition, some dUTP escape hydrolysis by dUTPase causing a certain amount of dUMP introduced into DNA opposite adenine during replication (Kornberg \& Baker, 1992). Irrespective of its mode of appearance, uracil is removed from the DNA in virtually all cells by uracil-DNA glycosylase (UDG) enzymes (EC 3.2.2.27) initiating the base excision repair pathway (Lindahl, 1993). The resulting abasic or apurinic/apyrimidinic site is subsequently removed by downstream incising/ excising functions and the integrity of DNA is finally restored by DNA polymerase and DNA ligase (Krokan et al., 1997). Since the discovery of the first (family 1) UDG in Escherichia coli more than three decades ago (Lindahl, 1974), numerous such enzymes have been characterized as well as at least 4 other families (families 2-5) have been added to the list of UDGs (Chung et al., 2003; Pearl, 2000; Sartori et al., 2002).

The rate of DNA-cytosine deamination is considerably higher at high compared to moderate temperatures (Frederico et al., 1990; Lindahl \& Nyberg, 1974), thus adding to the challenge of genomic maintenance in hyperthermophilic organisms (for a review on DNA repair in hyperthermophilic archaeons we refer to: Grogan, 2004). UDG activity in hyperthermophilic microor- ganisms was first reported in 1996 (Koulis et al., 1996). The hyperthermophilic archaeon Archaeoglobus fulgidus, a strict anaerobe growing optimally at $83^{\circ} \mathrm{C}$ (Stetter, 1992), contains a family 4 type of UDG named Afung, which has been cloned and over-expressed in E. coli followed by biochemical characterization (Engstrom et al., 2012; Knævelsrud et al., 2001; Sandigursky \& Franklin, 2000). Recently, immunodepletion of UDG activity present in archaeal cell extract showed that Afung is the principal and probably the only UDG in A. fulgidus (Knævelsrud et al., 2010).

Here we demonstrate that the UDG activity in cell extracts (i.e., wild type or native enzyme; nAfung) exhibits temperature dependence similar to that of the recombinant enzyme (rAfung) (Knævelsrud et al., 2001), which reflects optimal growth temperature of $A$. fulgidus. This contrasts with the results showing a significantly different $\mathrm{pH}$ dependence of the activity of nAfung compared to rAfung, where nAfung has an optimal UDG activity much closer to-and thus exhibits increased adaptation to-the neutral cytosolic $\mathrm{pH}$ of $A$. fulgidus. The present report provides the first description of how nAfung activity is dependent on temperature and $\mathrm{pH}$.

\section{MATERIALS AND METHODS}

Enzymatic uracil release was analysed using cell extracts prepared from the A. fulgidus type strain VC16 (DSMZ 4303 (Stetter, 1992)) grown anaerobically under Ar at $83^{\circ} \mathrm{C}$, where the cells were harvested in the early stationary phase essentially as described previously (Knævelsrud et al., 2001). Protein concentration was determined as described (Bradford, 1976) using bovine serum albumin as the standard. To analyse temperature dependence, enzyme was incubated with $\left.{ }^{3} \mathrm{H}\right]$ uracil-DNA (2000 dpm, 2 pmol DNA-uracils; specific activity, 1110 $\mathrm{dpm} / \mathrm{pmol}$ ) for $10 \mathrm{~min}$ in $50 \mu \mathrm{L} 70 \mathrm{mM}$ Mops, $\mathrm{pH}$ 7.5, $1 \mathrm{mM}$ EDTA, $1 \mathrm{mM}$ dithiothreitol, $100 \mathrm{mM} \mathrm{KCl}$, $5 \%$ (v/v) glycerol (reaction buffer) (Knævelsrud et al., 2001). To analyse pH dependence, exactly the same incubation conditions were used except that in this case the reaction buffer was a modified universal buffer with different $\mathrm{pH}$ values (Bjelland \& Seeberg, 1987; Johnson \& Lindsey, 1939; Knævelsrud et al., 2001). The reactions were carried out at $80^{\circ} \mathrm{C}$ and $95^{\circ} \mathrm{C}$. The amount of radioactivity present in the supernatant was determined

e-mail: svein.bjelland@uis.no

Abbreviations: Afung, uracil-DNA glycosylase from Archaeoglobus fulgidus; nAfung, native Afung; rAfung, recombinant Afung; UDG, uracil-DNA glycosylase 
following DNA precipitation with ethanol, and control values from incubations without enzyme were subtracted (Knævelsrud et al., 2001). The intracellular pH of $A$. fulgidus was determined by ${ }^{31} \mathrm{P}$-nuclear magnetic resonance spectroscopy at SINTEF (The Foundation for Scientific and Industrial Research at the Norwegian Institute of Technology), Trondheim, Norway.

\section{RESULTS AND DISCUSSION}

Temperature dependence for the enzymatic uracil release by $A$. fulgidus was determined by incubating cell extracts (nAfung) with $\left[{ }^{3} \mathrm{H}\right]$ uracil-DNA from $20^{\circ} \mathrm{C}$ to $100^{\circ} \mathrm{C}$. The results show that UDG activity was detected at all temperatures but varied significantly (Fig. 1). Previously we described that the abrupt increase in activity of rAfung at $60^{\circ} \mathrm{C}$ was accompanied by a conformational conversion to a more open structure (Knævelsrud et al., 2001). The present results show that nAfung follows rAfung by exhibiting an abrupt increase in activity at $60^{\circ} \mathrm{C}$ to reach its maximum around $80^{\circ} \mathrm{C}$ (Fig. 1); the latter corresponding neatly with the optimal growth temperature of $83^{\circ} \mathrm{C}$ for $A$. fulgidus. The activity decreases as the temperature approaches $100^{\circ} \mathrm{C}$, although providing a significant repair efficiency several degrees beyond the optimal growth temperature. Since the A. fulgidus cell extracts were routinely prepared from cells grown at the optimal temperature, we were also curious as to whether the growth temperature might influence the in vivo level of UDG activity. However, extracts prepared from cells grown at $60^{\circ} \mathrm{C}, 83^{\circ} \mathrm{C}$ and $90^{\circ} \mathrm{C}$ showed similar levels of UDG activity, as measured at all these three different temperatures (data not shown), arguing against afung gene induction or repression as a response to temperature changes.

Then, the $\mathrm{pH}$ dependence for the enzymatic release of uracil from $\left[{ }^{3} \mathrm{H}\right]$ uracil-DNA by cell extracts was determined. The results show a peak of maximal activity at $\mathrm{pH}$ 6.2, which is quite different from rAfung which exhibits the highest activity at pH 4.8 (Fig. 2) (Knævelsrud et al., 2001). Importantly, it has been reported that $\mathrm{pH}$ optima of proteins measured in vitro are dependent on storage $\mathrm{pH}$ (Behzadi et al., 1999), which was 6 for rAfung and 7.5 for nAfung (Knævelsrud et al., 2001). Theoretically, this might have influenced our results. However, since the $\mathrm{pH}$ optimum changes inversely with storage $\mathrm{pH}$ (Behzadi et al., 1999), it would, in our case, imply that the difference in $\mathrm{pH}$ optimum between rAfung and nAfung should be even larger if UDG activity was determined after storage of the two Afung preparations at exactly the same $\mathrm{pH}$. In conclusion, nAfung as compared to rAfung exhibits maximal activity at a $\mathrm{pH}$ significantly closer to the intracellular $\mathrm{pH}$ of $A$. fulgidus, which was determined to be $7.0 \pm 0.1$ at $61^{\circ} \mathrm{C}$ (not shown).

In spite of our demonstration of a significant enzymatic difference between Afung in cell extracts (nAfung) and the E. coli-produced rAfung protein (Fig. 2), no difference in their molecular weights has been observed (Knævelsrud et al., 2010). Alternative folding of nAfung and rAfung facilitated by different chaperone functions in so distantly related organisms as $A$. fulgidus and E. coli (Lund, 2011), where the proteins are produced under extremely different temperature conditions, could in principle explain such a major change in function without an accompanying mass change. This also accords with quite different kinetic parameters determined for nAfung and rAfung (Knævelsrud et al., 2010). However, alternative folding patterns to be stably perpetuated at high

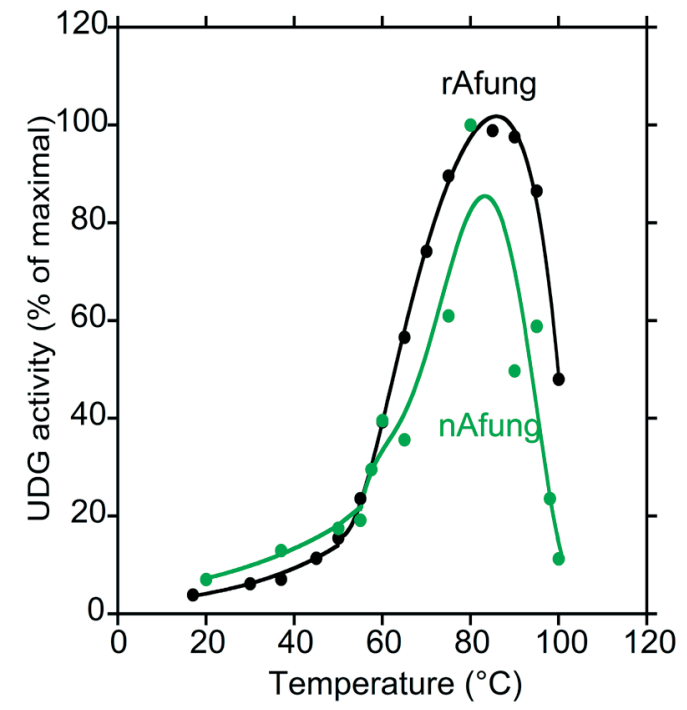

Figure 1. Temperature dependence for the excision of uracil from DNA by $A$. fulgidus cell extracts (nAfung, $O$ ) compared to rAfung (O)

Cell extracts (1-4 $\mathrm{\mu g}$ protein) were incubated with $\left[{ }^{3} \mathrm{H}\right] \mathrm{ura}$ cil-DNA as described in Materials and Methods. Each value represents the median of $4-33(0$, maximum $=100 \%)$ or $4[0.9$ pmol enzyme; , maximum $=100 \%$ (Knævelsrud et al., 2001)] independent measurements.

temperature sound unlikely, especially for Afung, which we found, as mentioned above, to convert to a more open structure during transition from low to high temperature (Knævelsrud et al., 2001). Another possibility, although in our opinion also quite unlikely, is that Afung interacts with certain cellular components in a non-covalent manner in order to fulfil the requirements of the in vivo conditions. Interestingly, the human family 1 UDG (hUNG2) has recently been shown to be regulated by site-specific phosphorylations of Ser/Thr residues (Hagen et al., 2008). It is tempting to speculate whether

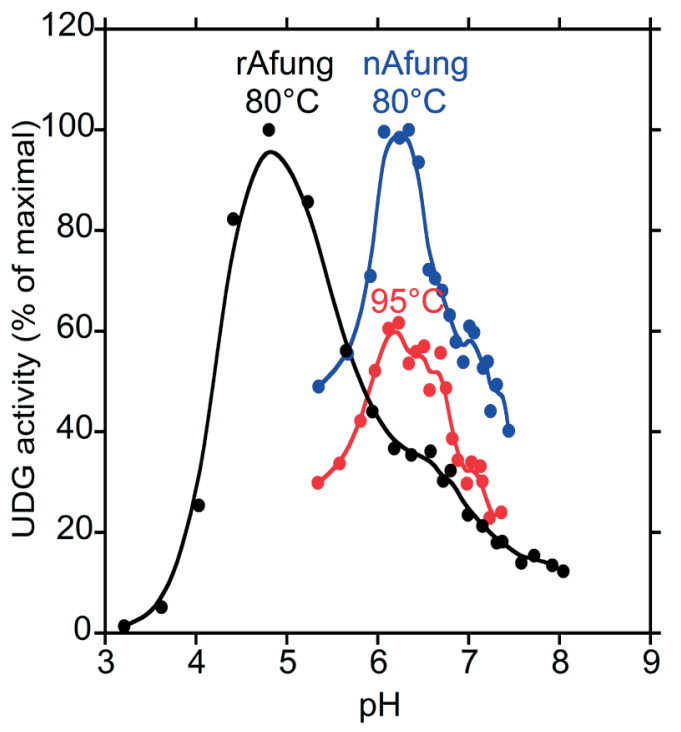

Figure 2. $\mathrm{pH}$ dependence for the excision of uracil from DNA by $A$. fulgidus cell extracts (nAfung, $\bigcirc$ ) compared to rAfung (O). Cell extracts (38 $\mu \mathrm{g}$ protein) were incubated with [3 $\mathrm{H}]$ uracil-DNA at $80^{\circ} \mathrm{C}(O)$ or $95^{\circ} \mathrm{C}(O)$ as described in Materials and Methods. Each value represents the median of $4-9(0$, maximum $=100 \%$; , $\%$ of maximum at $80^{\circ} \mathrm{C}$ ) or 3 [0.2 pmol enzyme; maximum $=100 \%$ (Knævelsrud et al., 2001)] independent measurements. 
serine-threonine kinases of $A$. fulgidus (LaRonde-LeBlanc et al., 2005a; LaRonde-LeBlanc et al., 2005b; Shi et al., 1998) may serve a similar role.

Afung is one of the most studied family 4 UDGs (Knævelsrud et al., 2010; Knævelsrud et al., 2001; Sandigursky \& Franklin, 2000), and is, due to the presence of a $[4 \mathrm{Fe}-4 \mathrm{~S}]^{2+}$ cofactor, redox-active when bound to DNA. Thus, together with some other DNA glycosylases, Afung has been studied in the context of an interesting theory on the involvement of redox activity and DNA-mediated electron transfer in DNA damage recognition (Boal et al., 2005; Engstrom et al., 2012). Our precise measurement of the optimal $\mathrm{pH}$ for Afung in cell extracts (nAfung) compared to purified enzyme (rAfung; Fig. 2) (Knævelsrud et al., 2001), together with the determination of intracellular $\mathrm{pH}$ of $A$. fulgidus, may aid the development of in vitro conditions that closer mimic in vivo electrolyte conditions for damage detection and excision.

We want to conclude the following. Although increase in cell temperature results in an increased DNA damage burden, in casu uracil, our results show that the expression of the afung gene does not seem to be affected by growth temperature. The catalytic function of nAfung has evolved to neatly adapt to the optimal growth temperature of $A$. fulgidus, because its temperature dependence can be explained by the characteristics of rAfung and thus the primary protein structure. Adaption of Afung to the neutral cytosolic $\mathrm{pH}$ can hardly be explained by afung gene alterations alone, and is likely provided by certain $A$. fulgidus in vivo reactions or accessory factors.

\section{Acknowledgements}

We are indebted to G. Falkeid and $\AA$. Østebø for technical assistance, to B. Kavli and G. Slupphaug for providing $\left[{ }^{3} \mathrm{H}\right]$ uracil-DNA and to $\mathrm{H}$. W. Anthonsen for determining intracellular $\mathrm{pH}$.

This research was supported by the Research Council of Norway (Grant No. 148997/432).

\section{REFERENCES}

Behzadi A, Hatleskog R, Ruoff P (1999) Hysteretic enzyme adaptation to environmental $\mathrm{pH}$ : Change in storage $\mathrm{pH}$ of alkaline phosphatase leads to a $\mathrm{pH}$-optimum in the opposite direction to the applied change. Biophys Chem 77: 99-109.

Bjelland S, Seeberg E (1987) Purification and characterization of 3-methyladenine DNA glycosylase I from Escherichia coli. Nucleic Acids Res 15: 2787-2801.

Boal AK, Yavin E, Lukianova OA, O'Shea VL, David SS, Barton JK (2005) DNA-bound redox activity of DNA repair glycosylases containing [4Fe-4S] clusters. Biochemistry 44: 8397-8407.

Bradford MM (1976) A rapid and sensitive method for the quantitation of microgram quantities of protein utilizing the principle of proteindye binding. Anal Biochem 72: 248-254.
Chung JH, Im EK, Park H-Y, Kwon JH, Lee S, Oh J, Hwang K-C, Lee JH, Jang Y (2003) A novel uracil-DNA glycosylase family related to the helix-hairpin-helix DNA glycosylase superfamily. Nucleic Acids Res 31: 2045-2055.

Engstrom LM, Partington OA, David SS (2012) An iron-sulfur cluster loop motif in the Archaeoglobus fulgidus uracil-DNA glycosylase mediates efficient uracil recognition and removal. Biochemistry 51: 5187-5197.

Frederico LA, Kunkel TA, Shaw BR (1990) A sensitive genetic assay for the detection of cytosine deamination: Determination of rate constants and the activation energy. Biochemistry 29: 2532-2537.

Grogan DW (2004) Stability and repair of DNA in hyperthermophilic archaea. Curr Issues Mol Biol 6: 137-144.

Hagen L, Kavli B, Sousa MML, Torseth K, Liabakk NB, Sundheim $\mathrm{O}$, Peňa-Diaz J, Otterlei M, Hørning O, Jensen ON, Krokan HE, Slupphaug G (2008) Cell cycle-specific UNG2 phosphorylations regulate protein turnover, activity and association with RPA. EMBO J 27: $51-61$.

Johnson WC, Lindsey AJ (1939) An improved universal buffer. Analyst (London) 64: 490-492.

Knævelsrud I, Moen MN, Grøsvik K, Haugland GT, Birkeland N-K, Klungland A, Leiros I, Bjelland S (2010) The hyperthermophilic euryarchaeon Archaeoglobus fulgidus repairs uracil by single-nucleotide replacement. J Bacteriol 192: 5755-5766.

Knævelsrud I, Ruoff P, Ånensen H, Klungland A, Bjelland S, Birkeland N-K (2001) Excision of uracil from DNA by the hyperthermophilic Afung protein is dependent on the opposite base and stimulated by heat-induced transition to a more open structure. Mutat Res 487: 173-190.

Kornberg A, Baker TA (1992) DNA Replication, 2nd edition. New York: W.H. Freeman.

Koulis A, Cowan DA, Pearl LH, Savva R (1996) Uracil-DNA glycosylase activities in hyperthermophilic micro-organisms. FEMS Microbiol Lett 143: 267-271.

Krokan HE, Standal R, Slupphaug G (1997) DNA glycosylases in the base excision repair of DNA. Biochem I 325: 1-16.

LaRonde-LeBlanc N, Guszczynski T, Copeland T, Wlodawer A (2005a) Autophosphorylation of Archaeoglobus fulgidus Rio2 and crystal structures of its nucleotide-metal ion complexes. FEBS J 272: 2800-2810.

LaRonde-LeBlanc N, Guszczynski T, Copeland T, Wlodawer A (2005b) Structure and activity of the atypical serine kinase Rio1. FEBS J 272: 3698-3713.

Lindahl T (1974) An N-glycosidase from Escherichia coli that releases free uracil from DNA containing deaminated cytosine residues. Proc Natl Acad Sci USA 71: 3649-3653.

Lindahl $T$ (1993) Instability and decay of the primary structure of DNA. Nature 362: 709-715.

Lindahl T, Nyberg B (1974) Heat-induced deamination of cytosine residues in deoxyribonucleic acid. Biochemistry 13: 3405-3410.

Lund P (2011) Insights into chaperonin function from studies on archaeal thermosomes. Biochem Soc Trans 39: 94-98.

Pearl LH (2000) Structure and function in the uracil-DNA glycosylase superfamily. Mutat Res 460: 165-181.

Sandigursky M, Franklin WA (2000) Uracil-DNA glycosylase in the extreme thermophile Archaeoglobus fulgidus. J Biol Chem 275: 1914619149.

Sartori AA, Fitz-Gibbon S, Yang H, Miller JH, Jiricny J (2002) A novel uracil-DNA glycosylase with broad substrate specificity and an unusual active site. EMBO J 21: 3182-3191.

Shi L, Potts M, Kennelly PJ (1998) The serine, threonine, and/or tyrosine-specific protein kinases and protein phosphatases of prokaryotic organisms: A family portrait. FEMS Microbiol Rev 22: 229-253. 